\title{
Application of near infrared spectroscopy to predict chemical composition and energy value of compound feeds for ruminants
}

\author{
J Aufrère, D Graviou \\ INRA, SRNH, Unité Valeur Alimentaire, Theix, 63122 St-Genès-Champanelle, France
}

\begin{abstract}
The energy of compound feeds for ruminants depends primarily on the digestibility of their organic matter (dOM), which can be predicted from various analytical criteria (chemical, microbiological and enzymatic). However, other constituents have to be assayed to predict the energy value expressed in digestible energy (DE), metabolisable energy (ME) or net energy expressed in UFL or UFV. Recently, near infrared spectroscopy (NIRS) was used to determine chemical composition with high accuracy and predict the digestibility and energy value of forages.

We compared this method with classical analytical methods for determining the chemical composition and energy value of compound feeds for ruminants.
\end{abstract}

We studied 80 samples of compound feeds for ruminants from four European laboratories, of in vivo measured digestibility. The methods used for the in vivo measurements and the assay of the various chemical constituents of these feeds, together with the predictions obtained using these chemical and enzyme methods on those 80 samples have been reported by Giger-Reverdin et al (1994, Anim Feed Sci Technol, 48, 73-98).

The absorbance spectra $(\log 1 / R)$ of the samples were measured by NIRS between 1100 and $2500 \mathrm{~nm}$. Regression equations were developed to determine chemical composition, gross energy (GE), dOM, energy digestibility (dE), DE and ME, or UFL and UFV values directly. Calibration was performed using various mathematical treatments on the first and second derivative spectra (ascending regression and least squares regression (MPLS)).

The predictive accuracy of NIRS for chemical composition depends on the precision of the laboratory analyses carried out on these feeds. Prediction is very high for crude protein (CP) (coefficient of variation : $\mathrm{CV}=2.8 \%$ ), pepsincellulase digestibility (dCell) $(\mathrm{CV}=1.22 \%)$, dOM (CV $=1.35 \%)$, GE (CV $=0.82 \%)$, DE $(\mathrm{CV}=1.7 \%)$, ME (CV $=1.80 \%)$, UFL $(\mathrm{CV}=$ $1.80 \%)$, UFV $(\mathrm{CV}=2.70 \%)$. Prediction of cellwall constituent levels, though less accurate than for forages, is still good : (CV $=5.4 \%$ for NDF, $4.4 \%$ for ADF, $14 \%$ for ADL).

The association of certain chemical criteria (NDF, ADF, ADL, fat) affords a prediction for dOM (RSD $=2.39$ ) that is as good as that afforded by dCell (RSD $=2.42$ ), but NIRS provided the best prediction $($ SEC $=1.1$ ). Likewise for the prediction of energy values by comparison with those obtained from the same chemical constituents plus the $\mathrm{CP}$ content $(S E C=56.0$ versus $R S D=110.0 \mathrm{kcal} \mathrm{ME} / \mathrm{kg}$ OM ; 0.02 for UFL versus $0.05 \mathrm{UFL} / \mathrm{kg} \mathrm{OM}$; 0.03 for UFV versus $0.06 \mathrm{UFV} / \mathrm{kg}$ OM). The coefficients obtained with the MPLS model and/or ascending regression (step-up model) show that wavelengths in the range 1200$1300 \mathrm{~nm}$ and $1600-1700 \mathrm{~nm}$ are among the most meaningful for the cell-wall constituents, $\mathrm{dOM}, \mathrm{dCell}, \mathrm{DE}$ and UF values.

In conclusion, NIRS proves much better than chemical assay for predicting digestibility and energy value of compound feeds for ruminants. 